\title{
Dental caries spectrum profile in Brazilian public school children and adolescents
}

\author{
Sofia Rafaela Maito VELASCO(a) iD \\ Gustavo Chab PISTELLI(b) iD \\ Fernanda Pátaro Marsola \\ RAZERA $^{(b)}$ \\ Rafael MENEZES-SILVA(c) iD \\ Roosevelt Silva BASTOS(b) iD \\ Maria Fidela de Lima \\ NAVARRO $^{(c)}$ iD \\ (a) Universidade de São Paulo - USP, Faculty of \\ Public Health, Department of Epidemiology, \\ São Paulo, SP, Brazil. \\ (b) Universidade de São Paulo - USP, Bauru \\ School of Dentistry, Department of \\ Pediatrics Dentistry, Orthodontics and Public \\ Health, Bauru, SP, Brazil. \\ (c) Universidade de São Paulo - USP, Bauru \\ School of Dentistry, Department of \\ Operative Dentistry, Bauru, SP, Brazil.
}

Declaration of Interests: The authors certify that they have no commercial or associative interest that represents a conflict of interest in connection with the manuscript.

Corresponding Author:

Sofia Rafaela Maito Velasco

E-mail: sofiamaito@hotmail.com

https://doi.org/10.1590/1807-3107bor-2021.vol35.0067

Submitted: June 2, 2020

Accepted for publication: December 7, 2020

Last revision: February15, 2020
Abstract: Dental caries remains a major public health problem, with a higher prevalence among in adolescence. The present study aimed to assess the dental caries spectrum profile in children and adolescents in Brazilian public schools. A cross-sectional study was performed in two public schools in Brazil to examine the permanent teeth of children and adolescents. The dental caries were assessed by applying the Caries Assessment Spectrum and Treatment (CAST) instrument, and the results were distributed as per disease status (healthy/codes 0-2; pre-morbidity/code 3; morbidity/code 4-5; severe morbidity/codes 6-7; mortality/code 8) and by severity as per the CAST-F1 formula (no severity, mild, moderate, and severe). The CAST data were described by age groups (8-9 y, 10-11 y, 12-13 y, 14-15 y, 16-17 y, and 18-19 y). The Kruskal-Wallis test was used to investigate differences in CAST prevalence and severity among the groups ( $p<0.05)$. Total 598 students were enrolled. Most of the subjects were male (53.34\%) and belonged to the age group of $12-13$ y $(34.95 \%)$. The variables CAST $0 / 1(p=0.024)$, CAST $(p=0.024)$, and CAST-F1 $(p=0.029)$ showed significant differences among age groups, and the post hoc test showed the differences in these variables as per the age groups of 14-15 y and 16-17 y (CAST $0 / 1, p=0.047$; CAST, $\mathrm{p}=0.047$; CAST-F1, $\mathrm{p}=0.033$ ). The dental caries spectrum increased from 8 to $19 \mathrm{y}$ with a peak in the prevalence and severity in the middle of adolescence.

Keywords: Dental Caries; Child; Adolescent; Index; Epidemiology.

\section{Introduction}

Dental caries is a sugar-dependent disease; therefore, with an acidogenic bacterial biofilm as the etiology for dental hard tissue degeneration. ${ }^{1}$ However, the multifactorial character of dental caries is also recognized, prompting several researchers to explore the sociodemographic variables. ${ }^{2,3,4}$ associated with dental caries, such as age..$^{5,6,7,8}$. Brazilian national oral health surveys have been officially observing dental caries in children and adolescents since $1986 .{ }^{9}$ The decline is evident in 12-year-old children and adolescents aged 15-19 y in these studies; however, there is a marked age increase in dental caries maintaining a proportion similar to $1: 2$ between children and adolescents (6.65:12.68-1986; $\left.;^{9} .78: 6.17-2003 ; ;^{10} 2.07: 4.25-2010^{11}\right)$. 
Many variables might be considered as predictors of dental caries throughout the period of adolescence, such as female sex, increased sugar intake, poor oral health self-assessment, dental visits, and ageing. ${ }^{12}$ In the previous Brazilian National Dental Survey ${ }^{11}$ of 2010, living in cities with fluoridated tap water, low coverage of water supply, and residing in low-median income municipalities were considered as contextual determinants. Moreover, non-Caucasian origin, belonging to a low-income family, and the presence of clinical conditions, such as dental calculus or bleeding gums, were associated with the individual determinants of dental caries in children aged $12 \mathrm{y}{ }^{4}$ In the Brazilian State of São Paulo, from 2002 to 2010, a decrease was recorded in the incidence of dental caries in children aged $12 \mathrm{y}$ old and in adolescents; however, in the group with few caries, tooth loss decreased, while the untreated dental caries and the need for treatment increased..$^{13}$ Untreated dental caries have been investigated in a systematic review with metaregression and the increase in the prevalence of dental caries peaked in those with permanent teeth, although not during adolescence. ${ }^{14}$ During this period of aging and in Brazilians, caries, the decline was unequal and influenced by schooling and family income. ${ }^{15}$ Dental caries can also be influenced by social determinants of health, and management strategies must include plans for prevention and assistance in absolute and relative ways; age plays an important role.

The Caries Assessment Spectrum and Treatment (CAST) was introduced in dental literature for epidemiologic purposes in $2011 .{ }^{16}$ Thereafter, validation studies. ${ }^{17,18}$ have confirmed its reliability for epidemiologic surveys and clinical studies. ${ }^{19}$ An important concern about a new index for dental caries assessment is associated with the comparability with previous published data. Moreover, Decayed Missing Filled Teeth (DMFT) has been widely used since 1937.20 Nevertheless, the CAST index is acceptable for comparison with the dental caries criteria proposed by the World Health Organization. ${ }^{21}$ In a recent study, CAST showed better properties for epidemiologic studies ${ }^{22}$ because the collection of data time was similar to DMFT, provided better distribution of the disease that enabled better observation for preventive and curative needs, from ICDAS, which was difficult to analyze and demanded more time to register data, and from DMFT, which was the fastest way to register data, however it underestimated caries prevalence). The hierarchical CAST design allows an evaluation of the severity categories (healthy-CAST 0 to 2; pre-morbidity-CAST 3; morbidity-CAST 4 and 5; severe morbidity-CAST 6 and 7; and mortality-CAST 8$)^{23}$. inally, the development of a formula called CAST-F1 allows the investigators to score the distribution into 3 severity categories (mild, moderate, and severe). ${ }^{24}$

Dental caries is an important chronic disease despite the important worldwide decrease in the prevalence in younger subjects observed in the previous decades. ${ }^{14}$ Throughout life, the occurrence of dental caries is expected to increase with age, as shown in diverse Brazilian national studies conducted in $1986,{ }^{9} 2003,{ }^{10}$ and $2010 .{ }^{11}$ Nevertheless, the investigation model proposed in these studies did not intend to survey subjects of every age, and it is unknown if this increase is constant or if there could be a peak of increase during adolescence. Therefore, we aimed to answer the following question: Is there a constant increase in dental caries from childhood to adolescence or there is a peak point of increase during adolescence?

\section{Methodology}

The study was conducted in Bauru (Brazil), a city located in the center-west of the State of São Paulo that had 343,937 inhabitants in 2010 as per the Brazilian DemoFigure Census; the estimated number of residents was 371,690 in 2017. This Census $(2010)^{25}$ registered 13,185 male and 12,734 female individuals in the age group of 10-14 y and 13,660 male and 13,039 female individuals aged 15-19 y. In 2015, Bauru had a school network that included 107 middle schools, distributed among private (38 schools with 10,609 enrollments) and public state administration (53 schools with 23,188 enrollments) plus 16 municipal public schools with 8,352 students. For high school, there were 27 private schools (3,024 enrollments) and 35 state public schools (11,450 enrollments), making a total of 62 schools (IBGE, 2017). Bauru city presented a 
Municipal Human Development Index (HDI) of 0.607 in 1991, 0.736 in 2000, and 0.801 in 2010. The Gini indexes for per capita household income were 0.524 for 1991, 0.583 for 2000, and 0.560 for 2010 . The sample was selected from two public schools in the outskirts of Bauru (Escola Estadual Francisco Alves Brizola and Escola Estadual Walter Barreto Melchert) in 2015.

\section{Ethical aspects}

This study was approved by a Brazilian Human Ethics Research Board (CAAE 24012913.0.1001.5417) and was conducted as per the World Medical Association Declaration of Helsinki. The participants or their legal guardians signed an informed consent, and every participant aged $<18$ y also signed an informed consent before the epidemiologic exams were conducted, complying with the Brazilian and international recommendation.

\section{Sampling}

For this observational cross-sectional analytics epidemiology study, the minimal sample size was based on a previous study ${ }^{26}$ on adolescents (15-19 y old) in the same city that showed a prevalence of $71.69 \%$ for dental caries. The sample calculus for this population survey was performed using software StatCalc/Epi Info T.M. 7.2.2.6. for a finite population of 1335 students enrolled in both schools. The criteria used in the calculus were a prevalence of $71.69 \%$, $5 \%$ for acceptable margin of error and 1.1 for design effect. The minimal population estimated for this study was 280 participants, with 140 from each school. This study was nested in a randomized controlled clinical trial for validation of the technique ART class II restorative in permanent teeth. ${ }^{27}$ Two public schools from the north city outskirts were chosen because of the higher incidence of dental caries in vulnerable communities that received assistance for dental caries as part of our research project; thus, every student ethically allowed to participate in the main study was examined.

\section{Inclusion and exclusion criteria}

All students aged 8-19 y old who were enrolled in the two public schools were eligible for study participation. The exclusion criteria established were the use of fixed orthodontic appliances and/or the participation in other health researches using medication or any dental treatment.

\section{Data collection}

Four dentists were the examiners and participated in a calibration process before the collection of the main data with same dental caries, environment, and procedures criteria. Two sessions were conducted in 2 don 15 students aged 14-17 years, they were chosen from caries free mouth to severe dental caries pattern, with the aim of predicting the most different clinical situations possibly found in the main survey. All the examinations were performed using the CAST methodology with participants seated in front of the dentist examiner in a room with artificial light, except plenty of natural light entering from a huge window in front of the participants. Every tooth was observed with a dental mirror number 5 and if necessary, a CPI probe was used, both sterilized. The first two rounds were discarded. The last round showed 0.95 for intra-examiners and 0.87 for the inter-examiners kappa statistics. During the main dental data collection, $10 \%$ of the participants were re-examined, and kappa statistical analysis was performed with a result of 0.84 . Before any dental examination, all the participants were invited to brush their teeth with a toothbrush filled with fluoride toothpaste (Colgate Triple Action ${ }^{\circledR}, 1,450$ ppm fluoride) and use dental floss after brushing, under the supervision of a dentist. Examiners used a coat and a mask, before and between each examination; the examiners discarded the procedure gloves, washed hands, and used fresh gloves after each procedures. After single use, all the instruments were gathered in a plastic box with enzymatic detergent and were cleaned and sterilized properly in an autoclave.

\section{Dental caries epidemiology}

Using the CAST methodology, ${ }^{16}$ each tooth received a score between 0 and 9, depending on the crown condition (Table1). All the outcomes studied originated from the same database from the dental caries survey conducted in both schools. Each tooth received the corresponding CAST code as per the observed dental condition during the examination. In order to obtain 
the total and the average value of the CAST per participant, the sum of the CAST codes and its mean values considered only CAST 2 to CAST 8 resulting in the CAST variable. The participants were also classified as per the highest observed CAST code, and then the mean value was obtained, thus providing the "maximum CAST" score variable. Severity categories were also differentiated as healthy (sum of CAST 0-2), pre-morbidity (CAST 3), morbidity (sum of CAST 4-5), severe morbidity (sum of CAST 6-7) and mortality (CAST 8). The severity variable "CAST-F1" was calculated by weighting each cast differently, as can be seen in the following formula: $0.25^{*}$ CAST $3+1{ }^{*}$ CAST $4+2 *$ CAST $5+4{ }^{*}$ CAST $6+$ $5^{*} \mathrm{CAST} 7+6^{*} \mathrm{CAST} 8^{24}$. This formula excluded sound, sealed, and filled teeth (CAST0, CAST1, and CAST2) and attributed a greater weight as the level of severity increased in each CAST. The CAST-F1 variable was classified as follows: no severity (CAST-F1 score $=0$ ), mild (CAST-F1 $0<$ score $\leq$ ), moderate (CAST-F1 $<$ score $\leq 16$ ), and severe (CAST-F1 score $>16) .{ }^{24}$

\section{Age}

Age information was collected using self-response from each participant aged 8-19y and then grouped into the following age groups: 8-9 $y, 10-11 y, 12-13 y$, 14-15 y, 16-17 y, and 18-19 y. These groups were established, considering the similar daily life events that might be occurring as per the psychological and physical aging process because the occlusal development to permanent dentition mainly considering second molar eruption was a slightly different in time for males and females, therefore improving statistical analyses.

\section{Statistical analysis}

The distribution of the variables CAST, CAST maximum and CAST-F1, did not present a normal curve when the Kolmogorov-Smirnov test was applied $(\mathrm{p}<0.05)$. The Kruskal-Wallis test $(\mathrm{p}<0.05)$, followed by Dunn's post hoc test, was applied to identify significant statistical relationships between age groups for each mean value of the CAST and its components, CAST maximum and the severity score of CAST-F1. The chosen methodology was only associated with the differences between 8-9 X 10-11; 10-11 X 12-13; $12-13 \times 14-15 ; 14-15 \times 16-17 ; 16-17 \times 18-19$ ( $<<0.05)$.

\section{Results}

A total of 598 participants were enrolled, and most of them were boys (53.34\%). The patient age ranged from 8-19y and was grouped as 8-9y, 10-11 y, 12-13 y, 14-15 y, 16-17 y, and 18-19 y. The age group of $12-13$ y comprised more subjects $(34.95 \%)$, as can be seen in Table 2 .

When the CAST mean value (standard deviation), median, and the CAST components (0/1 to 8$)$ values were compared among the age groups with the Kruskal-Wallis test, only the CAST and the CAST 0/1, CAST 3, and CAST 4 components presented a significant difference (Table 3). Dunn's post hoc test

Table 1. CAST codes and description.

\begin{tabular}{|c|c|c|}
\hline Characteristic & Code & Description \\
\hline Sound & 0 & No visible evidence of a distinct carious lesion \\
\hline Sealant & 1 & Pits and/or fissures are at least partially covered with a sealant material \\
\hline Restoration & 2 & A cavity is restored with an (in)direct restorative material \\
\hline Enamel & 3 & $\begin{array}{c}\text { Distinct visual change in enamel only; a clear caries-related discoloration is visible, with or without localized } \\
\text { enamel breakdown }\end{array}$ \\
\hline Dentine & 5 & Distinct cavitation into the dentine; the pulp chamber is intact \\
\hline Pulp & 6 & Involvement of the pulp chamber; distinct cavitation reaching the pulp chamber, or only root fragments are present \\
\hline Abscess/Fistula & 7 & A pus-containing swelling or a pus-releasing sinus tract related to a tooth with pulpal involvement \\
\hline Lost & 8 & The tooth has been removed because of dental caries \\
\hline Other & 9 & Does not match with any other descriptions \\
\hline
\end{tabular}


Table 2. Distribution of participants in the study, by age and sex

\begin{tabular}{|c|c|c|c|c|c|c|}
\hline \multirow{2}{*}{ Age (y) } & \multicolumn{2}{|c|}{ Female } & \multicolumn{2}{|c|}{ Male } & \multicolumn{2}{|c|}{ Total } \\
\hline & $n$ & $\%$ & $n$ & $\%$ & $n$ & $\%$ \\
\hline $8-9$ & 16 & 2.68 & 18 & 3.01 & 34 & 5.69 \\
\hline $10-10$ & 68 & 11.37 & 60 & 10.03 & 128 & 21.40 \\
\hline $12-13$ & 102 & 17.06 & 107 & 17.89 & 209 & 34.95 \\
\hline $14-15$ & 63 & 10.54 & 100 & 16.72 & 163 & 27.26 \\
\hline $16-17$ & 24 & 4.01 & 27 & 4.52 & 51 & 8.53 \\
\hline 18-19 & 6 & 1.00 & 7 & 1.17 & 13 & 2.17 \\
\hline Total & 279 & 46.66 & 319 & 53.34 & 598 & 100.00 \\
\hline
\end{tabular}

pointed out these differences between the 14-15 y and 16-17y age groups, regarding the same variables. Although an oscillation was observed in the CAST values among the age groups, it increased from 1.68 in those aged $8-9 y$ to 3.54 in those aged $18-19 y$, as shown Table 3.

In Table 4, the maximum CAST variable and its components (CAST 0/1 to 8) were also distributed by age group. For each component, the number of participants and its percentage from the total are shown. In the maximum CAST column, the mean value, standard deviation, and median of each age group have been presented. No significant difference was observed among the patients from different age groups for either the maximum CAST or its components.

The CAST methodology $y^{23}$ allows the following categorization of its components as per severity: healthy (CAST 0-2), pre-morbidity (CAST 3), morbidity (CAST 4-5), severe morbidity (CAST 6-7), and mortality (CAST 8). As shown in Figure 1, the healthy category, even though it presented a fluctuation in its values,

Table 3. CAST and CAST components values by age group of schoolchildren and adolescents.

\begin{tabular}{|c|c|c|c|c|c|c|c|c|c|}
\hline Age groups (y) & CAST 0/1 & CAST 2 & CAST 3 & CAST 4 & CAST 5 & CAST 6/7 & CAST 8 & CAST & CAST (median) \\
\hline \multicolumn{10}{|l|}{$8-9$} \\
\hline mean & 26.26 & 0.41 & 0.65 & 0.26 & 0.03 & 0.26 & 0.06 & 1.68 & \multirow{2}{*}{1} \\
\hline SD & 2.18 & 1.46 & 1.35 & 0.79 & 0.17 & 0.79 & 0.34 & 2.08 & \\
\hline \multicolumn{10}{|l|}{$10-11$} \\
\hline mean & 26.54 & 0.37 & 0.61 & 0.24 & 0.16 & 0.05 & 0.03 & 1.46 & \multirow{2}{*}{0} \\
\hline SD & 2.06 & 0.84 & 1.30 & 0.76 & 0.76 & 0.26 & 0.22 & 2.06 & \\
\hline \multicolumn{10}{|l|}{$12-13$} \\
\hline mean & 26.61 & 0.33 & 0.63 & 0.27 & 0.09 & 0.03 & 0.03 & 1.39 & \multirow{2}{*}{0} \\
\hline SD & 2.13 & 0.97 & 1.19 & 0.76 & 0.54 & 0.25 & 0.27 & 2.13 & \\
\hline \multicolumn{10}{|l|}{$14-15$} \\
\hline mean & 26.65 & 0.33 & 0.58 & 0.20 & 0.08 & 0.10 & 0.04 & 1.33 & \multirow{2}{*}{0} \\
\hline SD & 1.93 & 0.96 & 1.27 & 0.70 & 0.40 & 0.50 & 0.25 & 1.91 & \\
\hline \multicolumn{10}{|l|}{$16-17$} \\
\hline mean & 25.75 & 0.49 & 1.14 & 0.41 & 0.10 & 0.12 & 0.00 & 2.25 & \multirow{2}{*}{1} \\
\hline SD & 2.70 & 1.08 & 1.60 & 0.83 & 0.30 & 0.48 & 0.00 & 2.70 & \\
\hline \multicolumn{10}{|l|}{ 18-19 } \\
\hline mean & 24.46 & 0.69 & 1.62 & 0.77 & 0.15 & 0.08 & 0.23 & 3.54 & \multirow{2}{*}{3} \\
\hline SD & 3.31 & 2.21 & 1.45 & 1.36 & 0.38 & 0.28 & 0.83 & 3.31 & \\
\hline$p$-value* & 0.024 & 0.631 & 0.001 & 0.008 & 0.546 & 0.162 & 0.650 & \multicolumn{2}{|r|}{0.024} \\
\hline$p$-value** & 0.047 & - & 0.003 & 0.014 & - & - & - & \multicolumn{2}{|r|}{0.047} \\
\hline
\end{tabular}

*Kruskal-Wallis Test (e.g.,: CAST 0/1 [H (5) = 12,866; $\mathrm{p}<0.05]) ;{ }^{* *}$ Dunn's post hoc Test (CAST 0/1; 14-15X16-17); (CAST 3; 14-15X16-17); (CAST 4; 14-15X16-17); (CAST; 14-15X16-17). 
- Dental caries spectrum profile in Brazilian public school children and adolescents

Table 4. Maximum cast and its components distribution, by age groups.

\begin{tabular}{|c|c|c|c|c|c|c|c|c|c|}
\hline \multirow{2}{*}{ Age Groups (y) } & \multirow{2}{*}{$\begin{array}{c}\text { CAST } 0 \\
/ 1\end{array}$} & \multirow{2}{*}{ CAST 2} & \multirow{2}{*}{ CAST 3} & \multirow{2}{*}{ CAST 4} & \multirow{2}{*}{ CAST 5} & \multirow{2}{*}{$\begin{array}{c}\text { CAST } 6 \\
17\end{array}$} & \multirow{2}{*}{ CAST 8} & \multicolumn{2}{|c|}{ Maximum CAST } \\
\hline & & & & & & & & (mean;SD) & (median)* \\
\hline \multicolumn{10}{|l|}{$8-9$} \\
\hline$n$ & 14 & 3 & 8 & 3 & 1 & 4 & 1 & \multirow{2}{*}{$2.32 ; 2.34$} & \multirow{2}{*}{3} \\
\hline$\%$ & 41.18 & 8.82 & 23.53 & 8.82 & 2.94 & 11.76 & 2.94 & & \\
\hline \multicolumn{10}{|l|}{$10-11$} \\
\hline$n$ & 66 & 11 & 21 & 12 & 9 & 6 & 3 & \multirow{2}{*}{$1.86 ; 2.20$} & \multirow{2}{*}{0} \\
\hline$\%$ & 51.56 & 8.59 & 16.41 & 9.38 & 7.03 & 4.69 & 2.34 & & \\
\hline \multicolumn{10}{|l|}{$12-13$} \\
\hline$n$ & 112 & 17 & 36 & 26 & 10 & 4 & 4 & \multirow{2}{*}{$1.68 ; 2.04$} & \multirow{2}{*}{0} \\
\hline$\%$ & 53.59 & 8.13 & 17.22 & 12.44 & 4.78 & 1.91 & 1.91 & & \\
\hline \multicolumn{10}{|l|}{$14-15$} \\
\hline$n$ & 87 & 14 & 28 & 14 & 8 & 8 & 4 & \multirow{2}{*}{$1.77 ; 2.18$} & \multirow{2}{*}{0} \\
\hline$\%$ & 53.37 & 8.59 & 17.18 & 8.59 & 4.91 & 4.91 & 2.45 & & \\
\hline \multicolumn{10}{|l|}{$16-17$} \\
\hline$n$ & 23 & 0 & 11 & 8 & 5 & 4 & 0 & \multirow{2}{*}{$2.24 ; 2.20$} & \multirow{2}{*}{3} \\
\hline$\%$ & 45.10 & 0.00 & 21.57 & 15.69 & 9.80 & 7.84 & 0.00 & & \\
\hline \multicolumn{10}{|l|}{ 18-19 } \\
\hline$n$ & 3 & 1 & 2 & 5 & 1 & 0 & 1 & \multirow{2}{*}{$3.15 ; 2.27$} & \multirow{2}{*}{4} \\
\hline$\%$ & 23.08 & 7.69 & 15.38 & 38.46 & 7.69 & 0.00 & 7.69 & & \\
\hline
\end{tabular}

showed a decrease with an increase in age; there was no significant change in the pre-morbidity of the groups and the categories morbidity, severe morbidity and mortality increased with age.
Severity, assessed using the CAST-F1 formula, was also categorized, as can be seen in Figure 2. The variations for each severity category did not indicate a pattern for those aged 1-4 y. However, for

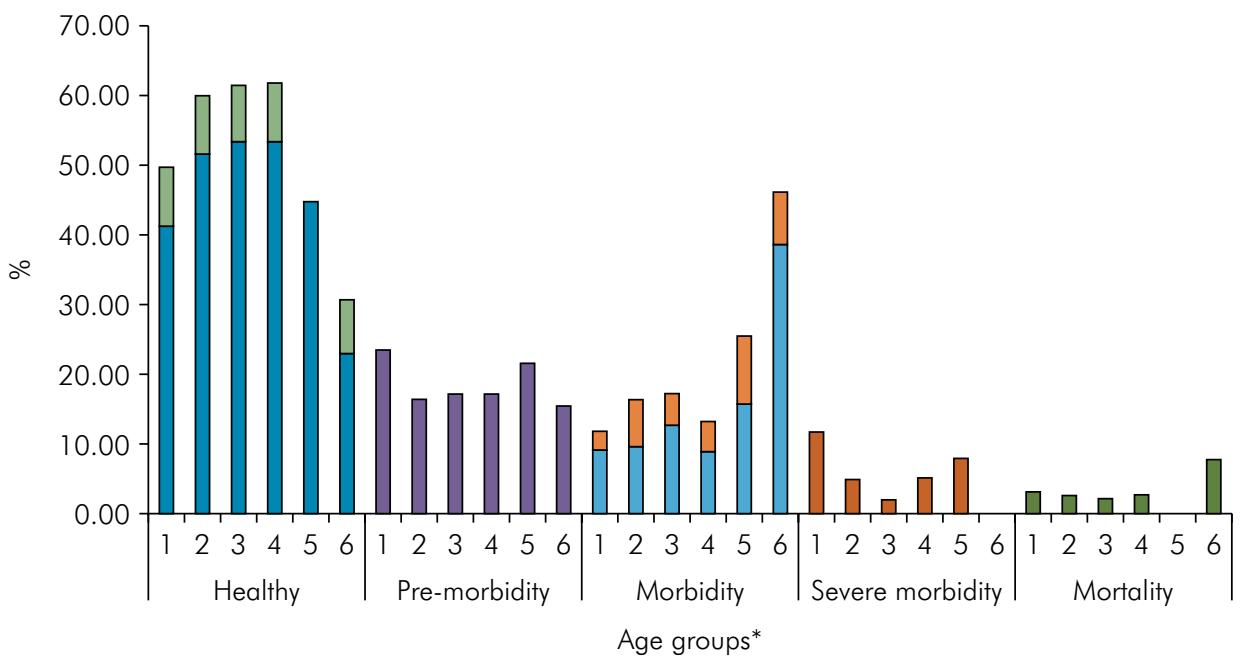

$\square$ CAST $0 \square$ CAST $1 \square$ CAST $2 \square$ CAST $3 \square$ CAST $4 \square$ CAST $5 \square$ CAST 6

CAST 7

$\square$ CAST 8

*Age Groups: $1: 8$ and 9 y; 2: 10 and 11 y; $3: 12$ and 13 y; $4: 14$ and 15 y; $5: 16$ and $17 y ; 6: 18$ and 19 y.

Figure 1. Percentual distribution of CAST components as per the category of severity in each age group. 
those aged 4-6y, the "no severity" category showed a remarkable fall, with an increase in the other severity categories, especially "mild severity" that showed an important increment. The "moderate" category presented a decreased tendency in those aged 1-3 y and a marked increase in those aged $4-5 \mathrm{y}$, followed by another decline at this point in those aged 6 y. Further, there was a greater increase in the "severe" category that was expressed more in the older age groups.

The variances observed in Figure 2 are shown in Table 5, displayed as per category (no severity, mild, moderate, and severe) and CAST-F1 mean and standard deviation values for each age group. A significant difference was observed only in the "CAST-F1" category with respect to its increase from $14-15$ to $16-17 \mathrm{y}$. This difference is also shown in Figure 3.

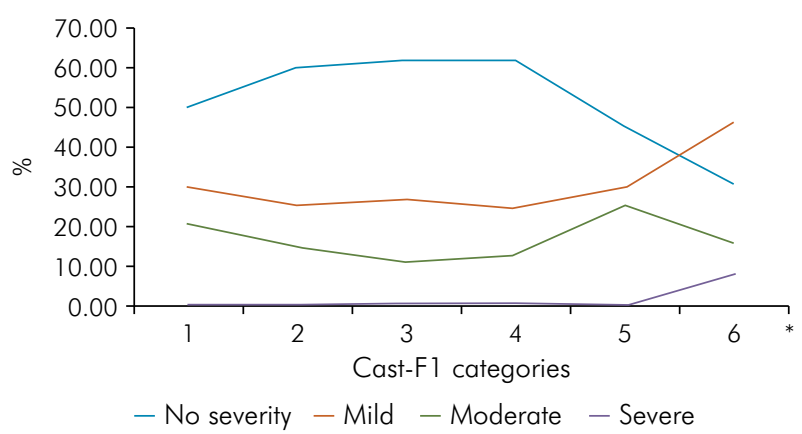

*Age Groups: $1-8$ and $9 ; 2-10$ and $11 ; 3-12$ and $13 ; 4-14$ and $15 ; 5-16$ and $17 ; 6-18$ and 19.

Figure 2. Percentual distribution of the severity score CAST-F1 and its categories, by age group.

\section{Discussion}

To our knowledge, this is the first study to analyze the prevalence and severity of dental caries from the new perspective of the CAST methodology. ${ }^{16,17,18,19,21,23,28}$ We reported data from the mean values of CAST and its components, maximum CAST and its components, CAST components by categories, and the severity by CAST-F1 formula ${ }^{24}$ with a new category of "no severity" in addition to the "mild" category. The prevalence of dental caries increases from childhood to adolescence, and this increase peaks during adolescence, from the age group of $14-15 \mathrm{y}$ to $16-17 \mathrm{y}$ in terms of prevalence and severity.

Despite the decline in the prevalence of dental caries in the permanent teeth of children and adolescents, current strategies to prevent the evolution of this disease from child hood to adolescence have not been successful. It is crucial to identify epidemiologic variables to understand this phenomenon in an absolute and relative manners. Therefore, dental caries

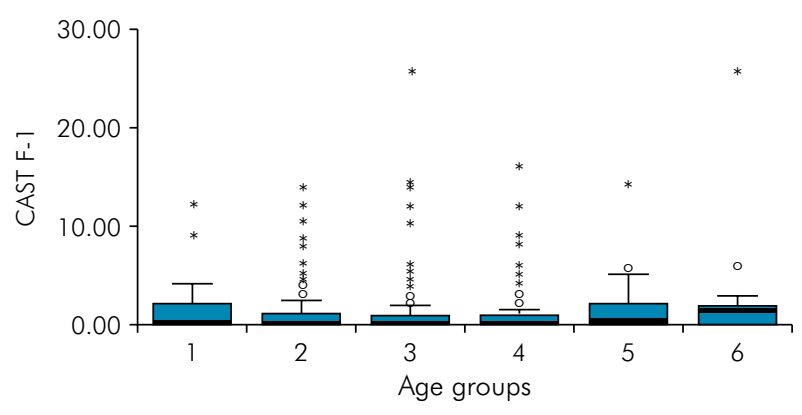

Figure 3. Means distribution of severity score as per CAST-F1, by age groups.

Table 5. Distribution of severity formula CAST-FI and its categories, by age group.

\begin{tabular}{|c|c|c|c|c|c|c|c|c|c|}
\hline \multirow{2}{*}{ Age Groups (y) } & \multicolumn{2}{|c|}{ No Severity } & \multicolumn{2}{|c|}{ Mild } & \multicolumn{2}{|c|}{ Moderate } & \multicolumn{2}{|c|}{ Severe } & \multirow{2}{*}{$\begin{array}{c}\text { CAST-Fl } \\
\text { mean (SD) }\end{array}$} \\
\hline & $n$ & $\%$ & $n$ & $\%$ & $n$ & $\%$ & $n$ & $\%$ & \\
\hline $8-9$ & 17 & 50.0 & 10 & 29.4 & 7 & 20.6 & 0 & 0.0 & $1.9(3.65)$ \\
\hline $10-11$ & 77 & 60.2 & 32 & 25.0 & 19 & 14.9 & 0 & 0.0 & $1.11(2.45)$ \\
\hline $12-13$ & 129 & 61.7 & 56 & 26.8 & 23 & 11.0 & 1 & 0.50 & $0.94(2.68)$ \\
\hline $14-15$ & 101 & 61.7 & 40 & 24.5 & 22 & 13.5 & 0 & 0.0 & $1.12(2.65)$ \\
\hline $16-17$ & 23 & 45.1 & 15 & 29.4 & 13 & 25.5 & 0 & 0.0 & $1.36(2.40)$ \\
\hline $18-19$ & 4 & 30.8 & 6 & 46.2 & 2 & 15.4 & 1 & 7.7 & 3.17 (6.97) \\
\hline$p$-value* & \multicolumn{2}{|c|}{1.000} & \multicolumn{2}{|c|}{0.791} & \multicolumn{2}{|c|}{0.300} & \multicolumn{2}{|c|}{1.000} & 0.031 \\
\hline $\mathrm{p}$-value** & & & & & & & & & 0.018 \\
\hline
\end{tabular}

*Kruskal-Wallis test; ${ }^{* *}$ Dunn's post hoc Test 
from childhood to adolescence might be combated by a population-based strategy with a risk strategy to reach this population group.

Important physiological and behavioral changes occur in the aging process from childhood to adolescence; these influence the increasing prevalence of caries. The main physiological change with respect to occlusion regards to the permanent dentition which is established after exfoliation of deciduous teeth and eruption of second permanent molars. These physiologic events are crucial because dental caries are generally more common on the occlusal surfaces, ${ }_{i}^{29}$ this fact should be considered while planning preventive strategies, such as daily toothbrushing with fluoridated dentifrice. However, this moment of transition in life also provokes important behavioral changes toward autonomy and independence. ${ }^{30}$ The use of fluorides in regular toothbrushing at home and mouth rinsing in professional offices are determinants of protection against dental caries for children and adolescents ${ }^{31}$. Adolescents tend to stop following their parents advice and assume behavior related to social determinants of caries experience, such as the consumption of sugary beverages, ${ }^{32}$ visiting the dentist only when experiencing pain, and disregarding regular check-ups or prevention sessions. ${ }^{31}$ These predictors are more commonly observed when parents, especially mothers, are less educated, ${ }^{31}$ as commonly found in vulnerable populations. Adolescents from lower socioeconomic status families, as from disengaged, separated or connected families are more likely to have larger number of cavitated lesions, ${ }^{33}$ supporting our study's findings.

Dental caries increases with age. Prospective studies have shown a significant correlation between early childhood caries (deciduous dentition) and caries in permanent dentition after $8 \mathrm{y}$ of observation; the same observation regarding caries free in deciduous and in permanent dentitions was reported in a Chinese children/adolescent study. ${ }^{34}$ In Germany, in a 15-year cohort study, irrespective of whether they were treated or untreated, early childhood caries resulted in severe dental caries during adulthood. ${ }^{35}$ These studies justify our study findings in terms of the increase of dental caries from childhood to adolescence, especially if the dental cavities were left untreated owing to the progressive nature of this disease.

The WHO strategy for age groups has not been revised, reinforcing the need for epidemiologic studies at each age, starting from childhood; this would provide accurate, detailed, and comprehensive data regarding the prevalence and severity of caries and would facilitate policy makers. The participants of this study were students from each age from 8-19y who were enrolled in public schools from vulnerable neighborhoods of the same town. The dental caries prevalence for those aged 16-17 y increased as compared to those for subjects aged 12-13 y, similar to the increase observed from 12 to $15-19 \mathrm{y}$ of age in the most recent Brazilian National Oral Health Survey, ${ }^{11}$ i.e., a proportion of 1 to 2 . Nevertheless, the increase was found to peak from 14-15 y to the 16-17 $y$ of age, reinforcing the external validity of these data and inducing the following question: What could be the determinants of such variations at this particular moment of adolescence? The answer cannot be supported only by inequalities because in this study, the result was observed in the entire cohort. The highest increase in dental caries might be associated with lower family income or education lateness or delay subgroups. ${ }^{15}$

Another concern is related to the methodology used in this study with respect to the CAST index. An epidemiologic index must be simple to understand with codes and clear criteria to ensure a reliable survey. Dental caries have been reported with success using the DMFT index since $1937,{ }^{20}$ with some improvements in recent years. ${ }^{36,37}$ In contrast, the CAST index registers dental caries in a different, hierarchical manner, with the possibility of comparing the new index results with those of the DMFT index..$^{21}$ Moreover, in the CAST index, untreated dental caries are registered from several components, allowing the researchers and policy makers to determine the prevalence of the disease as per its stages as follows: whether in the enamel, in the dentine (two stages), or reaching the dental pulp. The DMFT index does not register enamel caries; thus, for comparison, it is only necessary to sum codes 2 (filled), 4-7 (untreated dental caries), and 8 (lost) to have DMFT result, which corresponds in our study to 0.75 for $14-15$ age group, per example. 
Knowledge of the disease stage is crucial for health policies because dental caries treatment varies as per its severity in terms of procedures, materials used, and the final cost. The CAST index may also enable the study of dental caries via its maximum CAST score registered in an individual or at a population level.

The CAST categories reported lower levels of healthy individuals after the age of 14-15y; consequently, an increase is shown in the pre-morbidity, morbidity, and severe morbidity categories for those groups. The only exception was observed in those aged 16-17 y and $18-19 \mathrm{y}$, where there was an obvious reduction in the number of subjects categorized with pre-morbidity, allowing an increase in the more severe categories, especially morbidity.

The results from the CAST-F1 variable confirmed these observations by showing that there was an increase in the values of almost all the severity categories from the age group of 14-15 y to 18-19 y, except for the "no severity" one that presented a contradictory trend. This information is extremely relevant because it shows the importance of conducting oral health care programs with educational and preventive measures in middle and high schools to lower the prevalence and severity of dental caries in the later years of high school.

Certain limitations of the present study must be discussed. Although the results of increased prevalence of dental caries in this study from childhood to adolescence were similar to those reported by the Brazilian National Oral Health National Surveys, it would be interesting to adjust and analyze the collected data in the context of important variables, such as family income, schooling years, and family participation in Brazilian government aid programs as "Bolsa Família." In addition, the sample from the last National Survey was collected from the homes of the participants where it was possible to enroll informally working adolescents or those who were not enrolled in any school. However, the increase in dental caries increase at a proportion of 1:2 from 12 to $15-19$ y of age is well documented since the first Brazilian National Oral Health Survey in 1986. Further research is necessary to assess other individual variables, such as adolescent educational attainment in middle school, family wages and its social capital, and contextual factors related to the geographical location of private and public schools, and primary health attention access, such as Family Health Strategy in Brazilian public health system.

As dental caries in children and adolescents decline, many places are reaching DMFT around 1 (one) with prevalence $<30 \%$; therefore, the DMFT and $\mathrm{SiC}$ Index are becoming with similar results, CAST-F1 might be a reasonable way to provide a new epidemiological parameter to establish preventive measures for dental caries control and prevention in young populations with low dental caries prevalence and severity.

\section{Conclusion}

In this study, the dental caries spectrum presented an increase peak in prevalence and severity during the middle of adolescence, and the CAST index appeared appropriate for performing surveillance of dental caries.

\section{Acknowledgments}

This research was supported by the São Paulo Research Foundation (FAPESP, grant 2014/01626-3), and the authors are thankful for the collaboration of the leaders of the public schools, parents/tutors and participants in this study.

\section{References}

\footnotetext{
1. Fontana M, Young DA, Wolff MS, Pitts NB, Longbottom C. Defining dental caries for 2010 and beyond. Dent Clin North Am. 2010 Jul;54(3):423-40. https://doi.org/10.1016/i.cden.2010.03.007

2. Marmot M. Social determinants of health inequalities. Lancet. 2005 Mar;365(9464):1099-104. https://doi.org/10.1016/S0140-6736(05)71146-6

3. Baldani MH, Mendes YB, Lawder JA, Lara AP, Rodrigues MM, Antunes JL. Inequalities in dental services utilization among Brazilian low-income children: the role of individual determinants. J Public Health Dent. 2011;71(1):46-53. https://doi.org/10.1111/j.1752-7325.2010.00201.x
} 
4. Freire MoC. Reis SC, Figueiredo N, Peres KG, Moreira RaS, Antunes JL [Individual and contextual determinants of dental caries in Brazilian 12-year-olds in 2010]. Rev Saude Publica. 2013 Dec;47 Suppl 3:40-9. Portuguese. https://doi.org/10.1590/S0034-8910.2013047004322

5. Kramer ACA, Pivodic A, Hakeberg M, Östberg AL. multilevel analysis of dental caries in swedish children and adolescents in relation to socioeconomic status. Caries Res. 2019;53(1):96-106. https://doi.org/10.1159/000489570

6. Kumar S, Kumar A, Badiyani B, Kumar A, Basak D, Ismail MB. Oral health impact, dental caries experience, and associated factors in 12-15-year-old school children in India. Int J Adolesc Med Health. 2017 Apr;29(2):20150041. https://doi.org/10.1515/ijamh-2015-0041

7. Staberg M, Norén JG, Gahnberg L, Ghaderi A, Kadesjö C, Robertson A. Behavioural characteristics in externalising children with low and elevated risk for dental caries. Eur Arch Paediatr Dent. 2016 Dec;17(6):475-84. https://doi.org/10.1007/s40368-016-0256-6

8. Östberg AL, Kjellström AN, Petzold M. The influence of social deprivation on dental caries in Swedish children and adolescents, as measured by an index for primary health care: The Care Need Index. Community Dent Oral Epidemiol. 2017 Jun;45(3):233-41. https://doi.org/10.1111/cdoe.12281

9. Ministério da Saúde (BR). Secretaria Nacional de Programas Especiais de Saúde. Divisão Nacional de Saúde Bucal. Levantamento epidemiológico em saúde bucal: Brasil, zona urbana. 1986. Brasília, DF: Ministério da Saúde; 1988.

10. Ministério da Saúde (BR). Secretaria de Atenção à Saúde. Departamento de Atenção Básica. Projeto SB Brasil 2003: condições de Saúde bucal da população brasileira 2002-2003: resultados principais. Brasília, DF: Ministério da Saúde; 2004.

11. Ministério da Saúde (BR). Secretaria de Atenção Básica/Secretaria de Vigilância em Saúde. Departamento de Atenção Básica. Pesquisa Nacional de Saúde Bucal SB Brasil 2010: resultados principais. Brasília, DF: Ministério da Saúde; 2011.

12. Hu J, Jiang W, Lin X, Zhu H, Zhou N, Chen Y, et al. Dental caries status and caries risk factors in students ages 12-14 years in Zhejiang, China. Med Sci Monit. 2018 Jun;24:3670-8. https://doi.org/10.12659/MSM.907325

13. Sousa MLR, Rando-Meirelles MPM, Tôrres LHN, Frias AC. [Dental caries and treatment needs in adolescents from the state of São Paulo, Brazil]. Rev Saude Publica. 2013 Dec;47 Suppl 3:50-8. https://doi.org/10.1590/S0034-8910.2013047004340

14. Kassebaum NJ, Bernabé E, Dahiya M, Bhandari B, Murray CJ, Marcenes W. Global burden of untreated caries: a systematic review and metaregression. J Dent Res. 2015 May;94(5):650-8. https://doi.org/10.1177/0022034515573272

15. Roncalli AG, Sheiham A, Tsakos G, Watt RG. Socially unequal improvements in dental caries levels in Brazilian adolescents between 2003 and 2010. Community Dent Oral Epidemiol. 2015 Aug;43(4):317-24. https://doi.org/10.1111/cdoe.12156

16. Frencken JE, Amorim RG, Faber J, Leal SC. The Caries Assessment Spectrum and Treatment (CAST) index: rational and development. Int Dent J. 2011 Jun;61(3):117-23. https://doi.org/10.1111/j.1875-595X.2011.00022.x

17. Souza AL, Sanden WJ, Leal SC, Frencken JE. The Caries Assessment Spectrum and Treatment (CAST) index: face and content validation. Int Dent J. 2012 Oct;62(5):270-6. https://doi.org/10.1111/j.1875-595X.2012.00121.x

18. Souza AL, Leal SC, Chaves SB, Bronkhorst EM, Frencken JE, Creugers NH. The Caries Assessment Spectrum and Treatment (CAST) instrument: construct validation. Eur J Oral Sci. 2014 Apr;122(2):149-53. https://doi.org/10.1111/eos.12116

19. Souza AL, Bronkhorst EM, Creugers NH, Leal SC, Frencken JE. The caries assessment spectrum and treatment (CAST) instrument: its reproducibility in clinical studies. Int Dent J. 2014 Aug;64(4):187-94. https://doi.org/10.1111/idj.12104

20. Klein H, Palmer CE. Dental caries in American Indian children. Washington, DC: GPO; 1937. (Public Health Bulletin).

21. Souza AL, Leal SC, Bronkhorst EM, Frencken JE. Assessing caries status according to the CAST instrument and WHO criterion in epidemiological studies. BMC Oral Health. 2014 Sep;14(1):119. https://doi.org/10.1186/1472-6831-14-119

22. Castro AL, Vianna MI, Mendes CM. Comparison of caries lesion detection methods in epidemiological surveys: CAST, ICDAS and DMF. BMC Oral Health. 2018 Jul;18(1):122. https://doi.org/10.1186/s12903-018-0583-6

23. Leal SC, Ribeiro AP, Frencken JE. Caries assessment spectrum and treatment (CAST): A novel epidemiological instrument. Caries Res. 2017;51(5):500-6. https://doi.org/10.1159/000479042

24. Ribeiro AP, Maciel IP, Hilgert ALS, Bronkhorst EM, Frencken JE, Leal SC. Caries assessment spectrum treatment: the severity score. Int Dent J. 2018 Apr;68(2):84-90. https://doi.org/10.1111/idj.12331

25. Instituto Brasileiro de Geografia e Estatística - IBGE. Sinopse do Censo Demográfico 2010. Rio de Janeiro: IBGE; 2011.

26. Bastos RS, Carvalho ES, Xavier A, Caldana ML, Bastos JR, Lauris JR. Dental caries related to quality of life in two Brazilian adolescent groups: a cross-sectional randomised study. Int Dent J. 2012 Jun;62(3):137-43. https://doi.org/10.1111/j.1875-595X.2011.00105.x

27. Menezes-Silva R, Velasco SR, Bastos RS, Molina G, Honório HM, Frencken JE, et al. Randomized clinical trial of class II restoration in permanent teeth comparing ART with composite resin after 12 months. Clin Oral Investig. 2019 Sep;23(9):3623-35. https://doi.org/10.1007/s00784-018-2787-1

28. Frencken JE, Souza AL, Sanden WJ, Bronkhorst EM, Leal SC. The Caries Assessment and Treatment (CAST) instrument. Community Dent Oral Epidemiol. 2013 Feb;41(1):e71-7. https://doi.org/10.1111/cdoe.12027

29. Marthaler TM. Changes in dental caries 1953-2003. Caries Res. 2004 May-Jun;38(3):173-81. https://doi.org/10.1159/000077752

30. Curtis AM, Cavanaugh JE, Levy SM, VanBuren J, Marshall TA, Warren JJ. Examining caries aetiology in adolescence with structural equation modelling. Community Dent Oral Epidemiol. 2018 Jun;46(3):258-64. https://doi.org/10.1111/cdoe.12359 
31. Vadiakas G, Oulis CJ, Tsinidou K, Mamai-Homata E, Polychronopoulou A. Socio-behavioural factors influencing oral health of 12 and 15 year old Greek adolescents. A national pathfinder survey. Eur Arch Paediatr Dent. 2011 Jun;12(3):139-45. https://doi.org/10.1007/BF03262795

32. Skinner J, Byun R, Blinkhorn A, Johnson G. Sugary drink consumption and dental caries in New South Wales teenagers. Aust Dent J. 2015 Jun;60(2):169-75. https://doi.org/10.1111/adj.12310

33. Dutra LD, Neves ÉT, Lima LC, Gomes MC, Forte FD, Paiva SM, et al. Degree of family cohesion and social class are associated with the number of cavitated dental caries in adolescents. Braz Oral Res. 2020 Apr;34:e037. https://doi.org/10.1590/1807-3107bor-2020.vol34.0037

34. Li Y, Wang W. Predicting caries in permanent teeth from caries in primary teeth: an eight-year cohort study. J Dent Res. 2002 Aug;81(8):561-6. https://doi.org/10.1177/154405910208100812

35. Jordan AR, Becker N, Jöhren HP, Zimmer S. Early childhood caries and caries experience in permanent dentition: a 15 -year cohort study. Swiss Dent J. 2016;126(2):114-9.

36. World Health Organization - WHO. Oral health surveys: basic methods. Geneva: World Health Organization; 1997.

37. World Health Organization - WHO. Oral health surveys: basic methods. 5th ed. Geneva: World Health Organization; 2013. 